\title{
Breast abscess due to Salmonella Typhimurium in a patient with rheumatoid arthritis: a case report
}

\author{
Irmak Baran ${ }^{*}$, Neriman Aksu and Altan Aksoy
}

\begin{abstract}
Background: This is the first report of breast abscess due to Salmonella enterica serotype Typhimurium. Staphylococcus aureus is known as the most common cause of breast abscess. Salmonella spp. may occasionally form localized abscesses after dissemination to various organ systems following a bacteraemia. But breast abscess related to Salmonella spp is a very rare complication.
\end{abstract}

Case presentation: A 43-year-old female patient referred to our hospital with a lump, fever and mild pain in her breast. The patient was not pregnant or lactating at that time. She had a history of rheumatoid arthritis for 5 years and was under immunosuppressive therapy. Ultrasonography of the breast revealed an abscess. The abscess was drained and sent for culture to medical microbiology laboratory. The microorganism was identified as Salmonella enterica serotype Typhimurium and found to be sensitive to all antibiotics tested. The patient was cured after surgical debridement and antibiotic therapy. The abscess did not recur again.

Conclusions: This case is presented to draw attention to non-typhoidal Salmonella as rare causes of breast abscess and submission of specimens to the microbiology laboratory for accurate diagnosis and treatment especially in patients with underlying immunosuppressive diseases.

Keywords: Salmonella Typhimurium, Breast abscess, Rheumatoid arthritis, Extraintestinal salmonellosis, Case report

\section{Background}

Infections caused by bacteria belonging to Salmonella genus can be presented in five different clinical forms. These are enteric fever, sepsis, enterocolitis, localized organ disease and chronic carrier state [1,2]. Salmonella spp. are facultative intracellular bacteria. But they can also live freely [3]. They can survive in reticuloendothelial system macrophages and can spread by circulation. If the infection is untreated or resistant to treatment, circulating bacteria can settle in various organs and cause extraintestinal disease $[2,4,5]$.

The pathogenesis of extraintestinal Salmonella infections is affected by inoculum size of the ingested bacterium, virulence of the strain, local defence mechanisms and host's immune response [6]. Advanced age, gastric

\footnotetext{
* Correspondence: irmakmor@yahoo.com

Medical Microbiology Department, Ankara Numune Training and Research Hospital, Hacettepe Mahallesi Talatpasa Bulvari No:44, Altindag 06100, Ankara, Turkey
}

(c) 2016 The Author(s). Open Access This article is distributed under the terms of the Creative Commons Attribution 4.0 International License (http://creativecommons.org/licenses/by/4.0/), which permits unrestricted use, distribution, and reproduction in any medium, provided you give appropriate credit to the original author(s) and the source, provide a link to the Creative Commons license, and indicate if changes were made. The Creative Commons Public Domain Dedication waiver (http://creativecommons.org/publicdomain/zero/1.0/) applies to the data made available in this article, unless otherwise stated. etc.), immunosuppressive therapy malignancy (metastatic cancer, lymphoma, etc.), hemoglobinopathies, iv drug use, diabetes and passed trauma at the site of infection are risk factors blamed for localized extraintestinal Salmonella infections [2, 3, 7-9].

Staphylococcus aureus is the most common cause of breast abscess. Furthermore, streptococci, gram-negative bacilli, and anaerobes may cause breast abscess $[1,7,10$, 11]. Breast abscess due to Salmonella is rare and late complication of enteric fever [4]. Breast abscess were reported to develop after Salmonella enterica serotype Typhi and Paratyphi infections. But breast abscesses related to the non-typhoidal Salmonella are extremely rare $[1,8]$.

Here we present a case of breast abscess due to $S$. Typhimurium in a non-lactating 43-year-old female patient with rheumatoid arthritis (RA) and we have made a brief review Salmonella breast abscess cases in literature so far. 


\section{Case presentation}

A 43-year-old female patient referred to our hospital's emergency department in August 2014 with complaints of fever and severe pain in right breast. She noticed a soft lump and mild pain in her breast a week back. The intensity of pain increased gradually and for the last 2 days and her temperature increased. The patient had a history of 5 years of RA. The patient was not pregnant or lactating. She had three children with the last one delivered 6 years back.

On physical examination, the right breast was tender and swollen. A mobile, sensitive, soft, fluctuating mass of around 4 by $5 \mathrm{~cm}$ located in the right lower quadrant was palpable. The mass was not fixed to the upper skin. The upper skin was warm and erythematous. There was no nipple retraction or discharge from the nipple. Axillary lymph nodes were not palpable. The patient's respiratory, digestive, nervous system physical examinations were normal. Physical examination of the musculoskeletal system revealed swelling in $2^{\text {nd }}$ and $3^{\text {rd }}$ proximal interphalangeal joints of the right hand and swelling and limitation of motion in the right knee.

Ultrasonography (USG) of the right breast revealed a heterogeneously hypoechoic deep-seated irregular collection of approximately $40 \times 38 \mathrm{~mm}$ size. The patient was diagnosed with a breast abscess. The abscess was drained by USG guided drainage, and oral amoxicillin clavulanic acid $625 \mathrm{mg}$ bid therapy was started empirically.

The drained fluid was sent to medical microbiology laboratory in a tightly capped, sterile container. On macroscopic examination, it was observed that the material had yellowish cream colour and dense consistency. Gram staining of the material showed abundant polymorphonuclear leukocytes and gramnegative bacilli. The material was inoculated on $5 \%$ sheep blood and eosin methylene blue (EMB) agars plates. One of the sheep blood agar plates was incubated under anaerobic conditions. After incubation at $37^{\circ} \mathrm{C}$ for $24 \mathrm{~h}$ smooth, straight-edged colonies without hemolysis grew on sheep blood agar. On EMB agar, lactose-negative colonies were detected which tested negative for oxidase production. These colonies were identified as Salmonella species by Phoenix BD (Becton, Dickinson, USA) automated system and Salmonella group by Maldi-TOF MS (bioMérieux, France). The microorganism was identified as Salmonella enterica serotype Typhimurium according to the Kauffmann-White scheme by using specific antisera (Difco, Becton, Dickinson, USA). No anaerobic bacteria were isolated. The microorganism was found susceptible to ampicillin, ciprofloxacin, trimethoprimsulfamethoxazole, erythromycin, chloramphenicol, ceftazidime, and ceftriaxone by antibiotic susceptibility testing with Phoenix BD (Becton, Dickinson, USA) automated system.

The patient was called back to the surgical outpatient clinic to obtain a detailed history. It was learned that 2 months ago she had diarrhoea for approximately 3 days and did not receive any antibiotic treatment. The patient had RA for 5 years and was on prednisone therapy. There was no history of contact with animals or trauma to breasts. There was no history of similar swelling in the other breast; no history of diabetes mellitus, hypertension, bronchial asthma, and tuberculosis. When the patient's laboratory tests were examined leukocyte count was $12,400 / \mathrm{mm} 3$ (83.9 \% neutrophils), hemoglobin was $13.3 \mathrm{~g} / \mathrm{dL}$, fasting blood glucose was $108 \mathrm{mg} / \mathrm{dL}$, erythrocyte sedimentation rate was $31 \mathrm{~mm} / \mathrm{h}$, CRP was $32 \mathrm{mg} / \mathrm{l}$, RF was $28 \mathrm{IU} / \mathrm{ml}$ and anti CCP was $267.9 \mathrm{U} / \mathrm{mL}$. Alkaline phosphatase, amylase, aspartate aminotransferase, alanine aminotransferase, gamma-glutamyl transpeptidase, bilirubin levels were within normal limits. HBsAg, anti-HCV and anti-HIV (ETI-MAX 3000 analyzer; DiaSorin S.p.A., UK), anti-HBc (Cobas 6000 analyzer, Roche Diagnostics, USA) tests were found to be negative. Chest X-ray was normal. Stool, urine, and blood samples were obtained for culture and found negative for Salmonella spp. Gruber Widal test was also found negative. Figure 1 shows a timeline of events.

The patient was fully treated with the surgical draining of the breast abscess under general anaesthesia and oral ciprofloxacin $500 \mathrm{mg}$ twice daily. At the end of 2 weeks, the patient was fully healed with no clinical signs of abscess. The control examination with USG after 4 months showed no sign of recurrence of the abscess.

\section{Discussion}

Pregnancy, lactation, breast malignancy, hematoma, advanced age, gastric surgery, previous local trauma and drug abuse are known predisposing factors for breast abscess $[1,2,4,7,8]$. The case we reported here did not have any of these risk factors. But our patient had RA as an underlying disease and was using immunosuppressive drugs. RA patients have an increased risk of developing infectious diseases. The increased risk of infection in RA patients found to be associated with three factors: The nature of pathophysiology of the disease, comorbid chronic diseases and usage of immunosuppressive therapy for the treatment of the disease [12]. In recent studies, it is observed that immune system (especially $\mathrm{T}$ cells) ages prematurely in RA patients and they become inadequate in defence against infectious agents [13-16]. 


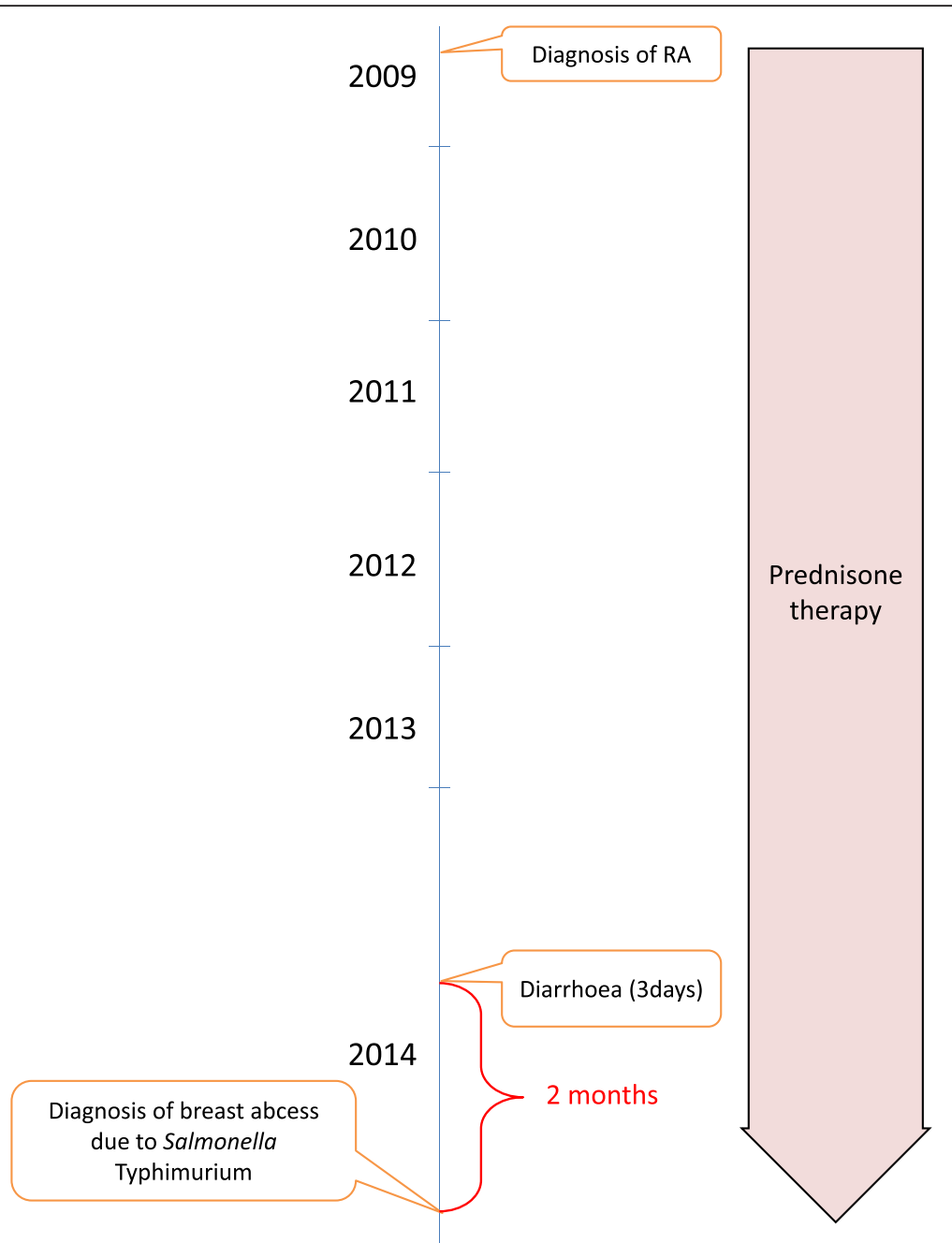

Fig. 1 Timeline of events since the patient was diagnosed with Rheumatoid arthritis (RA)

The patient had no history of contact with animals. When the patient's history was reviewed, it was revealed that the patient had an episode of gastroenteritis. We suppose the patient might have had a gastroenteritis related to Salmonella, but we cannot be sure since no stool sample was taken at the time of gastroenteritis. Focal salmonellosis is thought to occur secondary to bacteraemia after gastroenteritis. Patients with severe underlying conditions are known to be prone to focal infections [9]. The patient's breast might have became infected during a transient bacteriemic episode originating from patient's bowel and immunosuppressive state of the patient might have facilitated formation of the abscess. Localized Salmonella infection may occur after seeding of bacteria due to overt or silent bacteremia [1]. Secondary bacteremia develops in 3-8 \% cases of non-typhoidal Salmonella infection, and localized infection may only occur 5$10 \%$ of these [7]. Salmonella bacteremia in patients with severe immune system impairment found to be associated with increased risk of extraintestinal disease [7]. Previously extraintestinal Salmonella infections have been reported in patients who have had rheumatologic diseases (systemic sclerosis, systemic lupus erythematosus) and been receiving immunosuppressive therapy [2]. In our case, we think that having 5 years of RA and using immunosuppressive therapy might be contributing factors for formation of $S$. Typhimurium breast abscess.

$S$. Typhimurium had been isolated previously from septic arthritis, meningitis, hemorrhagic pleural effusion, brain abscess, parapharyngeal abscess $[2,9]$. We have done a literature review, and we concluded that this is the first case report of a breast abscess associated with $S$. Typhimurium.

When we made a literature review we found that the reported cases of breast abscess are mostly due to $S$. Typhi and Paratyphi infections. On the other hand, 
breast abscesses related to the non-typhoidal Salmonella isolates are very rare [8]. Table 1 shows the reports of breast abscess cases due to $S$. Typhi and Paratyphi infections when a literature search using Pubmed and Medline was done. It is interesting that most of the cases were from India where these infections are endemic. Typhoid breast abscesses have been reported to develop in $0.9 \%$ of the patients with generalized $S$. Typhi infections [1,7]. The first reported case of breast abscess was by Thayer and Hazen, who isolated $S$. Typhi from the breast abscess of a young housemaid presenting to the Johns Hopkins Hospital, Baltimore in 1907 [17]. Madelung had stated that until 1923 there were only 30 cases of Salmonella breast abscess case reports in the literature. Madelung ve Erbslöh said that in the breast abscess cases overlying skin was not erythematous and $S$. Typhi isolated from abscess was not in pure colony form, it was often part of a mixed growth. But later reports stated the opposite $[11,18]$. In our case, $S$. Typhimurium was isolated in pure culture form, and the overlying breast skin was erythematous. Klose ve Sebening stated in 1930 that mastitis develops in only $0.3 \%$ of the patients with typhoid fever. But Pezinski examined 1196 cases of typhoid fever in 1937 and determined that frequency of breast abscess in the general population was $0.5 \%$ and when only female patients were considered this frequency was $0.9 \%[11,18,19]$. Fernando et al. said that between 1970 and 2012, fewer than 15 breast abscess cases due to $S$. Typhi have been reported [4].

Breast abscess due to Salmonella spp. has also been observed in the neonatal period. Multi-drug resistant Salmonella isolation from breast abscesses has been reported. In a study Singh et al. retrospectively evaluated the reported cases of Salmonella breast abscess in the literature and concluded that most of the patients were between 23 and 45 years of age, immuno competent, non-lactating women. But they could not find a common predisposing factor [19].

There are few cases of breast abscess related to the nontyphoidal Salmonella isolates reported in the literature (Table 2). Edelstein et al. stated that until 1993 there were only six breast infection involvement cases related to nontyphoidal Salmonella isolates reported in the literature. Only two cases of these were breast abscesses the rest were mastitis cases [1]. Apart from the case which was reported in 2011 by Brncic et al, in none of the reported nontyphoidal Salmonella breast abscess cases the patient had a history of gastrointestinal disease. In contrast, our patient had a history of gastroenteritis passed 2 months ago.

\section{Conclusions}

Although non-typhoidal Salmonella spp. are rare causes of breast abscess they should be kept in mind

Table 1 Clinical features of reported cases of breast abscess due Salmonella enterica serotype Typhi and Paratyphi. (Source: PubMed, Medline)

\begin{tabular}{|c|c|c|c|c|c|c|c|}
\hline $\begin{array}{l}\text { Year of } \\
\text { publication }\end{array}$ & $\begin{array}{l}\text { Reference } \\
\text { number }\end{array}$ & Author & $\begin{array}{l}\text { Patient } \\
\text { age }\end{array}$ & Gender & Underlying condition & Species & $\begin{array}{l}\text { Unilateral/bilateral } \\
\text { breast abcess }\end{array}$ \\
\hline 1907 & {$[17]$} & Thayer and Hazen & 16 & Female & None & S. Typhi & Unilateral \\
\hline 1972 & [18] & $\begin{array}{l}\text { Barrett and } \\
\text { MacDermot }\end{array}$ & 43 & Female & None & S. Typhi & Unilateral \\
\hline 1994 & {$[20]$} & Lalitha and John & Unknown & Unknown & Unknown & S. Typhi & Unknown \\
\hline 2003 & [5] & Jayakumar et al. & 40 & Female & Fibroadenoma of the breast & S. Typhi & Unilateral \\
\hline 2007 & [21] & Delori et al. & 54 & Female & None & S. Typhi & Unilateral \\
\hline 2007 & {$[22]$} & Mahajan et al. & Unknown & Female & Immunocompromised & S. Typhi & Unilateral \\
\hline 2009 & [10] & Singh et al. & 35 & Female & None & S. Typhi & Bilateral \\
\hline 2011 & [19] & Singh et al. & 29 & Female & None & S. Typhi & Bilateral \\
\hline 2011 & [23] & Vattipally et al. & 28 & Female & None & S. Typhi & Unilateral \\
\hline 2012 & [4] & Fernando et al. & 33 & Female & None & S. Paratyphi A & Unilateral \\
\hline 2012 & [24] & Kumar et al. & 60 & Female & Diabetes Mellitus & S. Typhi & Unilateral \\
\hline 2012 & {$[25]$} & $\begin{array}{l}\text { Siddesh and } \\
\text { Sumana }\end{array}$ & 33 & Female & None & S. Paratyphi A & Unilateral \\
\hline 2013 & [11] & Banu et al. & 40 & Female & None & S. Typhi & Unilateral \\
\hline 2014 & {$[26]$} & Ghadage et al. & 31 & Female & None & S. Paratyphi A & Unilateral \\
\hline 2015 & [6] & Sood & 37 & Female & $\begin{array}{l}\text { Diabetes Mellitus Type } 2, \\
\text { hypothyroidism }\end{array}$ & S. Paratyphi A & Unilateral \\
\hline 2016 & [27] & $\begin{array}{l}\text { Elumalai and } \\
\text { Seetharaman }\end{array}$ & Unknown & Unknown & Unknown & S. Typhi & Unknown \\
\hline
\end{tabular}


Table 2 Clinical features of reported cases of breast abscess due non-typhoidal Salmonella isolates. (Source: PubMed, Medline)

\begin{tabular}{|c|c|c|c|c|c|c|c|}
\hline $\begin{array}{l}\text { Year of } \\
\text { publication }\end{array}$ & $\begin{array}{l}\text { Reference } \\
\text { number }\end{array}$ & Author & $\begin{array}{l}\text { Patient } \\
\text { age }\end{array}$ & Gender & Underlying condition & Species & $\begin{array}{l}\text { Unilateral/bilateral } \\
\text { breast abcess }\end{array}$ \\
\hline 1993 & [1] & Edelstein et al. & 28 & Female & None & $\begin{array}{l}\text { Salmonella serogroup B, } \\
\text { serotype Reading }\end{array}$ & Unilateral \\
\hline 2000 & {$[28]$} & Razeq et al. & 47 & Female & None & $\begin{array}{l}\text { Salmonella enterica serotype } \\
\text { Landwasser }\end{array}$ & Unilateral \\
\hline 2010 & {$[8]$} & Benwan et al. & 23 & Female & None & S. enterica serotype Poona & Bilateral \\
\hline 2011 & [7] & Brncic et al. & 70 & Male & Diabetes Mellitus Type 2 & $\begin{array}{l}\text { S. enterica serotype } \\
\text { Enteritidis }\end{array}$ & Unilateral \\
\hline 2014 & [29] & $\begin{array}{l}\text { Mohamed } \\
\text { and Asnis }\end{array}$ & 66 & Female & $\begin{array}{l}\text { Breast cancer and bilateral } \\
\text { breast implants }\end{array}$ & $\begin{array}{l}\text { S. enterica serotype } \\
\text { Enteritidis }\end{array}$ & Unilateral \\
\hline
\end{tabular}

when a breast abscess occurs in a patient who have immune suppressive diseases or in a patient who use immunosuppressive drugs. Therefore, breast abscess material of these patients should be sent to the microbiology laboratory for proper diagnosis or diagnosis can be missed.

\section{Abbreviations}

CCP, cyclic citrullinated peptide; CRP, C-reactive protein; EMB, eosin methylene blue; $\mathrm{HBC}$, hepatitis B core; HBsAg, hepatitis B surface antigen; HCV, hepatitis C virus; HIV, human immunodeficiency virus; Maldi-TOF MS, matrixassisted laser desorption/ionization mass spectrometry; RA, rheumatoid arthritis; RF, rheumatoid factor; USG, ultrasonography

\section{Acknowledgements}

The authors wish to acknowledge the patient.

\section{Funding}

The authors declare that funding was not utilized for the preparation of this manuscript.

\section{Availability of data and materials}

All available data is presented in the main paper.

\section{Authors' contributions}

IB was involved collection of the patient's data, conducting the literature review, doing laboratory tests, analysis of data and drafting of the manuscript. NA involved in supervision of the laboratory tests and revised crucially the manuscript for important intellectual content. AA involved in analysis of data and drafting of the manuscript. All authors read and approved the final manuscript.

\section{Competing interests}

The authors declare that they have no competing interests.

\section{Consent for publication}

Written informed consent was obtained from the patient for publication of this case report. A copy of the written consent is available for review by the Editor of this journal.

\section{Ethics approval and consent to participate}

Our ethics committee waived the requirement of ethics approval because all medical and laboratory procedures are routinely carried out and do not affect decisions concerning treatment.

Received: 4 April 2016 Accepted: 28 June 2016

Published online: 22 July 2016

\section{References}

1. Edelstein H. Breast abscess due to Salmonella serogroup B, serotype reading, in a young nonpuerperal woman. Clin Infect Dis. 1993;17:951-2.
2. Sudhaharan S, Padmaja K, Solanki R, Lakshmi V, Umabala P, Aparna B. Extraintestinal salmonellosis in a tertiary care center in South India. J Infect Dev Ctries. 2014;8:831-7.

3. MacLennan CA. Antibodies and protection against invasive salmonella disease. Front Immunol. 2014;5:635.

4. Fernando S, Molland JG, Gottlieb T. Failure of oral antibiotic therapy, including azithromycin, in the treatment of a recurrent breast abscess caused by Salmonella enterica serotype Paratyphi A. Pathog Glob Health. 2012;106:366-9.

5. Jayakumar K, Appalaraju B, Govindan VK. An atypical presentation of Salmonella typhi - a casereport. Indian J Med Microbiol. 2003;21:211-2.

6. Sood S. Breast abscess by Salmonella Paratyphi A: case report and literature review. J Clin Diagn Res. 2015;9:DD03-4.

7. Brncic N, Gorup L, Strcic M, Abram M, Mustac E. Breast abscess in a man due to Salmonella enterica serotype Enteritidis. J Clin Microbiol. 2012;50: 192-3.

8. Al Benwan K, Al Mulla A, Izumiya H, Albert MJ. Erythema nodosum and bilateral breast abscesses due to Salmonella enterica serotype Poona. J Clin Microbiol. 2010:48:3786-7.

9. Pastagia M, Jenkins SG. Salmonella neck abscess as an opportunistic infection in diabetes mellitus. Case Rep Infect Dis. 2013:2013:708419.

10. Singh S, Pandya Y, Rathod J, Trivedi S. Bilateral breast abscess: a rare complication of enteric fever. Indian J Med Microbiol. 2009;27:69-70.

11. Banu A, Hassan MM, Anand M. Breast abscess: sole manifestation of Salmonella typhi infection. Indian J Med Microbiol. 2013;31:94-5.

12. Listing J, Gerhold K, Zink A. The risk of infections associated with rheumatoid arthritis, with its comorbidity and treatment. Rheumatology (Oxford). 2013;52:53-61.

13. Koetz K, Bryl E, Spickschen K, O'Fallon WM, Goronzy JJ, Weyand CM. T cell homeostasis in patients with rheumatoid arthritis. Proc Natl Acad Sci U S A. 2000;97:9203-8.

14. Schönland SO, Lopez C, Widmann T, Zimmer J, Bryl E, Goronzy JJ, Weyand CM. Premature telomeric loss in rheumatoid arthritis is genetically determined and involves both myeloid and lymphoid cell lineages. Proc Natl Acad Sci U S A. 2003;100:13471-6.

15. Schmidt D, Goronzy JJ, Weyand CM. CD4+ CD7-CD28- T cells are expanded in rheumatoid arthritis and are characterized by autoreactivity. J Clin Invest. 1996:97:2027-37.

16. Wagner UG, Koetz K, Weyand CM, Goronzy JJ. Perturbation of the T cell repertoire in rheumatoid arthritis. Proc Natl Acad Sci U S A. 1998;95:14447-52.

17. Thayer WS, Hazen HH. Calcification of the breast following a typhoid abscess. J Exp Med. 1907:9:1-17.

18. Barrett GS, MacDermot J. Breast abscess: a rare presentation of typhoid. Br Med J. 1972;2:628-9.

19. Singh G, Dasgupta M, Gautam V, Behera A, Ray P. Bilateral breast abscesses due to Salmonella Enterica Serotype Typhi. J Glob Infect Dis. 2011;3:402-4.

20. Lalitha MK, John R. Unusual manifestations of salmonellosis-a surgical problem. Q J Med. 1994;87:301-9.

21. Delori M, Abqueguen P, Chennebault JM, Pichard E, Fanello S. Breast abscess with Salmonella typhi and review of the literature. J Gynecol Obstet Biol Reprod (Paris). 2007;36:709-12.

22. Mahajan RK, Duggal S, Chande DS, Duggal N, Hans C, Chaudhry R. Salmonella enterica serotype Typhi from a case of breast abscess. J Commun Dis. 2007;39:201-4. 
23. Vattipally V, Thatigotla B, Nagpal K, Saraiya R, Henry M, Shah AK, Cosgrove J. Salmonella typhi breast abscess: an uncommon manifestation of an uncommon disease in the United States. Am Surg. 2011;77:E133-5.

24. Kumar ES, Selvam RE, Ramesh SS. Salmonella enterica serovar Typhi in breast abscess: a case report. Indian J Pathol Microbiol. 2012;55:608-9.

25. Siddesh G, Sumana MN. A case of breast abscess due to Salmonella Paratyphi A. Int J Health Allied Sci. 2012;1:109-11.

26. Ghadage DP, Wankhade AB, Mali RJ, Bhore AV. Recurrent breast abscess due to Salmonella Paratyphi A: an unusual case. Int J Res Med Sci. 2014;2:1236-8.

27. Elumalai S, Seetharaman S. Molecular analysis of fluoroquinolone resistance in Salmonella enterica serovar Typhi from a breast abscess case. Indian J Pathol Microbiol. 2016;59:261.

28. Razeq JH, Glenn A, Thomas G, Sholes A. First human case of Salmonella enterica serotype Landwasser recovered from breast fluid. J Clin Microbiol. 2000;38:4300.

29. Mohamed M, Asnis D. A geriatric breast abscess due to Salmonella enteritidis. Clin Microbiol. 2014;3:5.

Submit your next manuscript to BioMed Central and we will help you at every step:

- We accept pre-submission inquiries

- Our selector tool helps you to find the most relevant journal

- We provide round the clock customer support

- Convenient online submission

- Thorough peer review

- Inclusion in PubMed and all major indexing services

- Maximum visibility for your research

Submit your manuscript at www.biomedcentral.com/submit
Biomed Central 